\title{
DIVERSITY MANAGEMENT AND PERFORMANCE: EVIDENCE FROM NIGERIAN MULTINATIONAL COMPANIES
}

Samuel Olufemi Omoyele*iD, Jayeola Olabisi** iD

DOI: $10.51558 / 2303-680 X .2020 .18 .2 .31$

\section{Abstract}

This study examines the relationship between diversity management and the performance of Nigerian multinational companies. A single crosssectional design was adopted for the study and a well-structured questionnaire was administered to 318 randomly chosen senior managers from Mobil Oil, Guinness, Coca-Cola, Nestle, MTN, and Cadbury Plc within Lagos Metropolis. The research instrument was tested for validity and reliability using confirmatory factor analysis and Cronbach's alpha. The independent variable is diversity management while performance (dependent variable) was measured with Employees' Productivity (EP), Profitability Level $(P L)$, and Employees' Innovativeness (EINV). The data collected were analyzed using Correlation Analysis and Structural Equation Modelling (SEM) factor to determine the relationship between diversity management and performance of Nigerian Multinational Companies. The results revealed a significant and positive relationship between diversity management and the performance of Nigerian multinational companies. The study concluded that diversity management motivates employees to put in their best to achieve a high level of productivity which leads to improved profitability due to employees' innovativeness. Therefore, the study suggests that multinational companies in Lagos Metropolis should ensure proper management of diversity in the workplace.

Keywords: diversity, productivity, profitability, and innovativeness

JEL: M14, M52, M150

\section{Introduction}

Diversity in the workplace is inescapable in trade liberalization, economic integration, and globalization. Workforce diversity intertwines with organization performance to the extent that any organization that pays little or no attention to policies on diversity may suffer all sorts of suppression, pressure, inclusion and exclusion, groupism, and unconscious discrimination that have a momentous impact on employees' relationship that affect productivity, profitability, and innovativeness. Globalization has triggered a massive shift in business practices that recognize and promote the uniqueness of different groups of a diverse workforce, especially multinationals. Diversity management focuses on the planning and implementation of business systems and practices to administer the workforce to the fullest to obtain maximum potential advantages of diversity. An area that provides focus on the dealings of measurement and control by the organization is a specialized field for diversity managers and diversity task force.

Diversity is a consent that reveals the heterogeneity in an individual's gender, race, religion, status, ethnicity, age, beliefs, orientation, and social-economic status. Amidst diversity, most Nigerians working in multinational companies are discriminated against based on diversity to an extent that most senior employees in multinationals are white, and that promotion and salaries reveal the white supremacies over the black (Ohunakin et al., 2019). In Western Europe and other developed parts of the world, workplace diversity management has received appropriate attention while it is not so in developing countries especially in Nigeria. The significance of diversity among the workforce has not been identified in multinational companies in Nigeria where there is a multidiverse workforce. Workplace diversity describes differences among individuals in an organization and goes beyond how individuals identify themselves to how others perceive

Department of Business Administration and Marketing, Redeemer's University, Nigeria, olufemi5ng@gmail.com

** Department of Accounting, Federal University of Agriculture, Abeokuta, Nigeria, olabisij@funaab.edu.ng 
them (Lane \& Flowers, 2015). Thus, the complex and ambiguous nature of most organizations leads to high work pressure and strong competition. Therefore, some organizations find it necessary to adopt a global culture aimed at motivating and attracting talents from various parts of the world devoid of incompatibility.

Panda (2010) argues that organizations are increasingly becoming multifaceted and vague, with great pressure of work, due to stiff rivalry, which has dictated the need for a global culture suitable for enticing and motivating diverse employees from different parts of the world. It is noteworthy that several issues act as barriers to diversity at work which includes discrimination, structural and procedural. In most workplaces, prejudice and bias, either conscious or unconscious exist, which is linked to discrimination and has negative outcomes on organization profitability, employees' innovativeness, and productivity (Jones et al., 2016). Issues are contributing to inequality, ranging from lack of women in leadership positions to perceptions of disabled job applicants, which adversely affects organizational performance. This implies that biases and discrimination due to improper management of diversity is a chief challenge that hinders organization performance in terms of profitability enhancement, employees' innovativeness, and productivity.

Despite the benefits of performance (improved profitability, employees' innovativeness, and productivity) attached to a diverse workforce, there are challenges. Demographic diversity may create a high level of conflict, tension, and employees' turnover. It is not enough for organizations to hire a diverse workforce to achieve organization survival but to properly manage the workforce. This implies that for organizations to benefit from a diverse workforce, conflicts and tension should be managed in a culturally sensitive manner. There have been remarkable studies and academic debates on the benefits of diversity management which have tangible and intangible benefits to the workplace such as improved profitability, employees' innovativeness, and productiveness (Samuel \&Odor, 2018; Inegbedion, Sunday, Asaleye, Lawal \& Adebanji, 2020). However, this study is neither too narrow nor too broad and can hardly be generalized in every context especially in Nigeria, where diversity is multifaceted and broad. It encompasses ethnicity, gender, race, disability, religion, age, sexual orientation, and difference in languages, economic, and organizational cultures.

As documented in the study carried out by the Society for Human Resource Management (2009), only 47 countries recognize global diversity. Nigeria took $45^{\text {th }}$ positionand is identified to be the most diverse population in the continent of Africa. Nigeria is known to have a diverse population with various religions coupled with diverse tribal, ethnic social-economic conflicts. Six multinational companies (Mobil Oil, Guinness, Coca-Cola, Nestle, MTN, and Cadbury Plc.) were chosen. Nigeria is densely populated with multinational companies with a diverse workforce. The selected companies are corporations consisting of a human force that provides a work environment for every individual regardless of gender, tribe, and religion.

Studies conducted on diversity-management and its impact on organizational performance produced mixed results (Powell, 2004; Richard, 2000). Cunningham (2009) affirmed that managing diversity in organizations has several advantages. Feldman (2005) posited that when the organization is proactive in diversity management, it results in productivity, innovativeness, and profitability enhancement. Feldman pointed out that this involves proper communication and the creation of an inclusive environment that motivates employees to put in their best to achieve a high level of performance. Kravitz and Yueling (2011) observed that a diverse workforce promotes innovativeness, profitability, and productivity.

However, there are insufficient empirical studies on diversity management and the performance of multinationals in developing countries specifically Nigeria. Against this bastion, the present paper aims at bridging the gap by examining the impact of diversity management on the performance of multinationals in Nigeria. 
The specific objectives are to:

- evaluate the impact of diversity management and employees' productivity of multinationals in Nigeria;

- investigate the relationship between diversity management and profitability level of multinationals in Nigeria; and

- assess the effect of diversity management on employees' innovativeness of multinationals in Nigeria.

The remaining parts of the paper deal with the review of extant literature while section three describes research methods employed. Section four discusses the results of the study and presented the findings of the study. The last section concluded the study and made recommendations.

\section{Literature review}

\subsection{Conceptual review}

The knowledge base of elements influencing performance has accumulated in literature. Most of the extant literature has directed attention to isolated factors and an all-inclusive perspective is found not adequate. More often, increasing emphasis is placed on diversity management and individual surrogates of performance. With this, the study seeks to examine the impact of diversity management on the identified measurements of performance (productivity, profitability, and innovativeness) of multinational companies in Lagos metropolis.

Dike (2013) described diversity management to be a process of planning, directing, organizing, and applying inclusive administrative qualities to build an organizational environment, where all diverse employees can keenly and efficiently add to the organizational competitiveness. Ajiri and Odor (2018) clarified diversity management as a designed responsibility of an organization to recruit a diverse mix of employees to combine and utilize the blend of the uniqueness of each culture.

Employee productivity is an evaluation of the efficiency of a worker or group of workers. Productivity is evaluated in terms of the output of an employee over a specific period and this is also called workplace productivity (Olabisi, Soyemi, \& Omojola, 2016). Employees' productivity is evaluated by observing every workforce or employee output in a given time. In most cases, the productivity of an individual workforce is assessed when compared with the average output of other employees on comparable work. Characteristically, employee productivity of a given worker is assessed by comparing the performance outcome of an individual employee with the relative average of another employee doing similar work. Employee productivity is an important consideration for businesses' performance because much of the success of any organization is dependent upon the productivity of its workforce. Richard (2000) asserted that organization that values diversity among its employees promotes productivity. It has been indicated in the literature that diversity management is significant to organizational productivity (Cunningham, 2009). The strength of a group is dependent on the porosity of the boundaries separating them to which end an organization is tasked with the role of weakening the boundaries and creating cohesion among the employees. Fields (2009) opined that a strong boundary and weak diversity can lead to several conflicts within the organization workforce with poor productivity among the workforce. The workforce is a productive asset of every organization that stimulates the company's product or service portfolio, and is capable of projecting or damaging the image of a company. Due to this prime importance of employees, a company that desires unprecedented growth should invest in its employees to obtain a return on that investment through improved productivity.

Profitability is the capability of a business to effectively use its scarce resources to produce returns that are more than expenses. In other words, it is a company's capability of generating profits from its operations. Raheman, Qayum and Afza, (2011) stated that every business is concerned with achieving a high level of profitability and profitability is the ability of a firm to earn returns on investment made in its assets that has a positive net present value. Olabisi, Afolabi, Kajola and Ariyibi, (2019) described firm profitability as the ability to generate revenue over operating 
expenses. McArthur (2010) cited in Ajiri and Odor (2018) asserted that ineffective diversity management can adversely affect the wellbeing of an organization and become a source of job dissatisfaction, thus causing a reduction in individual and group contribution to the organizational profitability. Organizational dimensions refer to those aspects relevant to the effective functioning of an organization itself such as position, work field, management status, unit or division, work field, and union affiliation. The process of managing diversity may be cumbersome as the inability to effectively manage diversity will affect profitability performance. The reduction in profitability performance may occur when individuals feel discriminated against based on gender, age, sex, and race.

Employee innovativeness is described as an assignation of innovative activities, which includes actions relating to the innovation process, i.e idea generation, and idea promotion to produce innovations (Kanter, 1988; Ramamoorthy, Flood, Slattery \& Sardessai, 2005). Innovation that deals with the implementation of novel ideas is considered to be either technological (changes in products, services, production processes) or administrative (changes in activities, social processes, structures). These are either radical or incremental, depending on the extent of their impact on prevailing products or processes (Damanpour, 1991). Employee innovativeness is assessed during the innovative process, from the initial idea generation to product development and eventually to product commercialization, to the implementation of new procedures or constructions in the organization (Axtell, Holman, Unsworth, Wall, Waterson \& Harrington 2000; Vincent, Decker \&Mumford, 2002). The effective management of diversity among the workforce affords a company to be advantageous in competition and improve employees' innovativeness (Kreitner \& Kinichi, 2004). Diversity management leads to improved innovativeness, as workforce diversity is the minor image of consumer diversity (Kanter, 2006). Ogbo, Kifordu, and Wilfred (2014) suggested that for diversity management to be effective, it is important to introduce effective education that enhances development and training exposure, as well as the promotion of employees' innovation towards the attainment of the organization set goals.

\subsection{Theoretical review}

The study is anchored on the socio-cultural theory that is contextualized as workplace learning in a diverse environment. This theory emerged from the Vygotskian view points of learning and expansion that emphasis on learning occurring within a social world (Alfred, 2002 cited in Gossen, 2016). Workplace diversity starts with activities, interactions, and communications established, basically among workers, managers, customers, and vendors, leading to knowledge. Socio-cultural learning comprises social activities such as teamwork or group projects which involve expressive interface encircling both social and cultural learning. This suggests that employees who involve in social activities within a diverse environment can improve considerations for each other, through interaction and teamwork in an inclusive workplace.

Workplaces that aim at benefiting from the diversity of the workforce are to take responsibility for ethical workplace learning in a socio-cultural rich context. To achieve this requires addressing socio-cultural development through the discovering of culture and diversity that help workers to identify with cultural identity and handle any challenge (Fenwick, 2001). Strategies to guarantee an effective diversified and inclusive workplace include the ability to connect the individual to the social context and interact with a specific context as well as structural dimensions such as race, class, gender, ethnicity, power, and oppression that account for social and cultural factors. Thus, the relationship between the individual and the workplace forms the basis of socio-cultural theory; and in the bid to engage and educate a diverse workforce, attention must be paid to the context and culture of the environment. For many workplaces, the shift to valuing context and socio-cultural perspectives is monumental. The 21st century has witnessed organizations' reformation of the workplace practices that can adapt to modern situations which necessitates creating an enabling environment that support 
the development of both individual employees and the business environment.

Solomon (2001), cited in Gossen (2016), viewed the new world of work as more than merely a physical restructuring of work practices, but rather a reformation of what aids the identity of the employees, such as actions and decisions. In other words, culture constitutes the patterns of meaning, beliefs, and values through which subjects (employees) understand their experience, develop a sense of belonging, and forge their sense of identity. Envisioning the workplace as a site of not just working, but also identitybuilding is a key factor that promotes strategies that engage worker's experiences and identities. This helps to maximize capacity utilization in the workplace (McIntyre \& Solomon, 2000 cited in Gossen, 2016).

\subsection{Previous research}

Jabbour, Gordono, Oliveira, Martinez, and Battistelle (2011) investigated the challenges and benefits of diversity management and human resource management in Brazilian companies and primary data were collected from 15 companies. The study found that the issue of diversity management in Brazilian companies was still evolving, with the major challenge being discrimination observed among coworkers. The study also found that out of the 15 companies investigated only four consistently adopted and practiced diversity management and human resources practices. These four companies supported the belief that incorporating sustainable diversity management requires strong support of the top management level in the organization.

Kundu and Mor (2017) examined workforce diversity and organizational performance of the Information Technology (IT) industry in India. The objective of the study was to assess the extent to which employee perceptions of diversity management impacted performance and if diversity management is related to the backgrounds in the Indian IT industry. Data were collected through a structured questionnaire administered to 402 respondents. The analysis was done using factor analysis, correlations, analysis of variance, means, grand means, and regression.
The study revealed an insignificant relationship between employees' backgrounds and diversity management. It however found that perceived promotion of gender diversity by employees had a positive and significant influence on performance. Suri and Sharma (2011) investigated diversity management and organizational effectiveness in public and private sector organizations in Indian organizations. The study selected 60 middlelevel managers from private and public firms in Delhi from whom data were collected for analysis. Data were analyzed using a t-test and correlation. The study found a significant difference between public and private sector organizations in diversity management while diversity management had a significant positive influence on the organizational effectiveness of private firms.

Inegbedion, Sunday, Asaleye, Lawal, and Adebanji (2020) examined the extent to which diversity management influences organizational efficiency through conflict management, teamwork, cultural diversity, employee work attitude, and perception of marginalization in Nigeria. Using a survey design, a sample size of 178 respondents was selected from nine multinational companies in South-South Nigeria. The data collected were analyzed using Structural Equation Modeling (SEM). The study found that the ability to effectively manage cultural diversity and employees' perception of marginalization had a significant influence on diversity management. Also, the study found that diversity management and teamwork significantly affect organizational efficiency.

Ohunakin, Adeniji, Ogunnaike, Igbadume, and Akintayo (2019) examined the effects of diversity management and inclusion on organizational outcomes among the employees of Shell Corporation in Nigeria. The study adopted a cross-sectional research design, and data were collected by means of the questionnaires administered to 384 respondents selected from the Lagos Branch of Shell Corporation. The data was analyzed using Confirmatory Factor Analysis (CFA), convergent and divergent validity, corelational analysis, and SEM. The study revealed a positive effect of diversity management and inclusion on employees' job 
satisfaction and job performance. The implication of such a finding is that diversity management and inclusion aid organizations to develop by motivating employees to improve productivity and innovativeness.

Odita and Egbule (2015) examined workforce diversity and organizational effectiveness in the Nigerian brewing industry. The questionnaire was adopted to collect data from 346 respondents selected through a stratified random sampling technique. The study made use of linear regression and correlation. The results of the study showed that workforce diversity has a significant and positive relationship with organizational effectiveness. The study specifically revealed cultural diversity to be more effective, and that team building and group training mediated between workforce diversity and organizational effectiveness.

\section{Methodology}

A single cross-sectional design was adopted to provide a correct explanation of the characteristics such as behavior, opinions, abilities, beliefs, and knowledge of a particular individual, situation, or group. The population of the study comprised six branches of multinational companies operating in Lagos Metropolis (Mobil Oil, Guinness, Coca-Cola, Nestle, MTN, and Cadbury Plc.). The reason for the selection of multinational companies was based on the fact that multinational companies have diverse employees. Lagos metropolis is selected because it is the largest economy in Africa with over $60 \%$ of industrial and commercial activities. Lagos is financially viable for it generates internal revenue of over $75 \%$ of federal grants derived from oil earnings. It is a metropolitan city with densely populated and widely built-up parts. Lagos is a major hub of the economy in Nigeria and the headquarters of national and global companies. It is the center for business and professional services that support the economic activities of Nigeria. With the population of over 16 million, Lagos occupies the position of the seventh fastest-growing city in the world and the second-largest in Africa.

A well-structured questionnaire was administered in 2019 to 318 (53 from each company) senior managers of multinational companies out of which 296 (representing 93.1\% return rate) were retrieved, processed, and analyzed. This proportion showed that the majority of the respondents were cooperative and responsive. The questionnaire was administered through the human resource department of the selected companies and online survey using survey monkey for convenience and wide coverage. The administration of questionnaires was followed up with in-depth interviews. The samples were randomly selected from the six multinationals using convenient sampling techniques based on tribes, culture, ethnicity, countries, and religions.

A well-structured five-point Likert scale questionnaire was adopted to measure respondents' opinions on various aspects of diversity management and performance (productivity, profitability, and innovativeness) from 5 ('strongly agree') to 1 ('strongly disagree'). The focus of the study was to examine the influence of diversity management on the performance of multinational companies. Lagos metropolis was considered as the study domain. The measuring instrument was divided into three parts (A-C). The first section of the questionnaire (part A) dealt with the respondents' demographic information. The second part (part B) addressed the question of diversity management and the third part (C) dealt with performance. Section (C) has three subsections which were surrogates of performance. The questionnaire was designed as an itemized rating scale with a brief description associated with each response category. It was typically arranged in a logical order and the respondents were required to select the categories that best describe their opinion to whatever rated in the questionnaire. The data collected were treated as an interval scale by using the approach to determine the total score for each respondent. A consistent scoring procedure was used from a high score (5) reflecting a favorable response to a low score (1) consistently reflecting an unfavorable statement.

The eight dimensions of diversity management of Larkey's (1996) Work Diversity Questionnaire (WDQ) were reviewed for 
adaptation. Also, the diversity management questionnaire was adapted from the questions on diversity management while inclusion was taken from Ohunakin, Adeniji, Ogunnaike, Igbadume, Akintayo's (2019) Diversity Management and Inclusion Questionnaire (DMIQ). The research instrument was tested for validity and reliability. CFA and Cronbach's Alpha were performed on the research instrument and three of the items were removed from WDQ and four of the items from (DMIQ) because their factor loadings were below the threshold of 70\% recommended by Fornell and Larcker (1981). Part C was subdivided into three and each with the questions on each of the three identified surrogates of performance (employees' productivity, profitability level, and employees' innovativeness).

Employees' productivity and profitability questionnaire was adapted from the questions on productivity and profitability from Olabisi, Soyemi, and Omojola's (2016) Productivity and Profitability Questionnaire (OOPPQ). Employees' innovativeness questionnaire was adapted from the questions on employees' innovation from Ramamoorthy, Flood, Slattery, and Sardessai's (2005) Employees' Innovativeness Questionnaire (RFSSEIQ). These adapted questions in the questionnaire were subjected to modifications while experts in psychometrics, evaluation, and measurement in the field of humanity and education management evaluated the questionnaire for clarity and content to remove ambiguity. The reason for performing CFA was to confirm the research instrument suitability given the Nigerian business environment. Cronbach's Alpha was used to test for reliability through the use of the results of a pilot study.

Descriptive and inferential statistics coupled with multiple regression analysis were adopted for analysis using SEM Lavaan software version 0.5. Besides, SEM factor analysis was also used to determine the relationship between diversity management and performance of Nigerian multinational companies.

Consequent upon this gap, the following hypotheses were formulated to guide the study
$\mathrm{Ho}_{1}$ : There is no significant impact of diversity management on employees' productivity in Nigerian multinational companies

$H a_{1}$ : There is a significant impact of diversity management on employees' productivity in Nigerian multinational companies

$\mathrm{Ho}_{2}$ : There is no significant relationship between diversity management and profitability level in Nigerian multinational companies

$\mathrm{Ha}_{2}$ : There is a significant relationship between diversity management and profitability level in Nigerian multinational companies

$\mathrm{Ho}_{3}$ : There is no significant effect of diversity management on employees' innovativeness in Nigerian multinational companies

$\mathrm{Ha}_{3}$ : There is a significant effect of diversity management on employees' innovativeness in Nigerian multinational companies.

\section{Data analysis and results}

Table 1 presents respondents' demographic information. It reveals that most of the respondents were male (64.1\%) indicating that more males work in multinational companies with varying levels of educational qualifications with the majority (58.2\%) having a master's degree. Their ages varied between 20 to above 51, with about 50.8\% in the age bracket between 31-40 yrs.

In summary, the respondents that participated in this study were well-educated, experienced, and from different ethnic groups, with good work experiences in the operation of multinational companies. 
Omoyele, S. O., Olabisi, J.

Table 1. Demographic characteristics of respondents

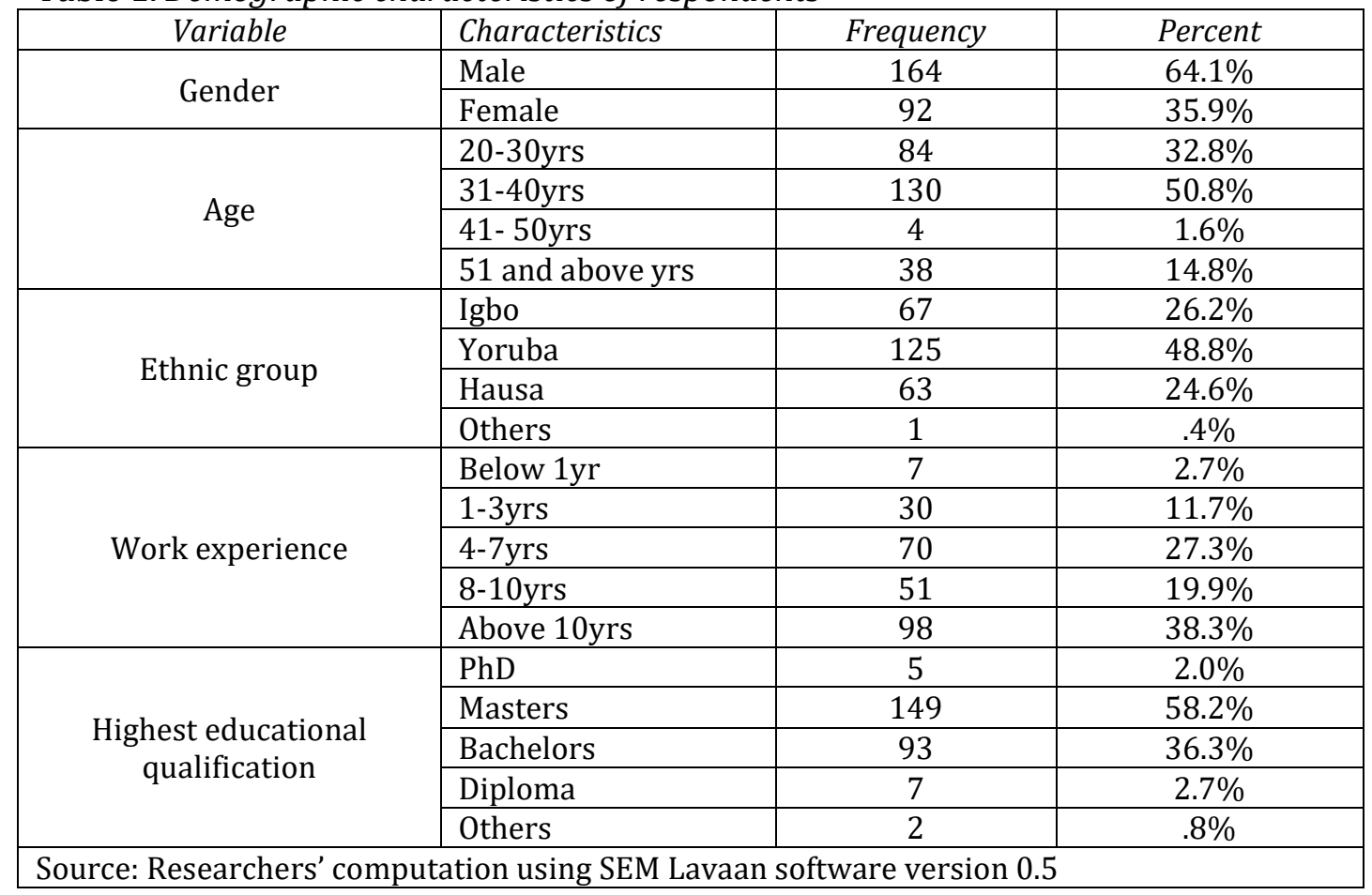

Table 2 is the descriptive statistics of the data adopted in the study. It tells the skewness and kurtosis of the data to account for the normality A value very close to zero, in both instances, signifies that the data is of the data spread.

normally distributed (Pallant, 2013).

Table 2. Descriptive statistics

\begin{tabular}{|c|c|c|c|c|c|c|c|c|}
\hline & \multirow{2}{*}{ Min } & \multirow{2}{*}{ Max } & \multirow{2}{*}{ Mean } & \multirow{2}{*}{ SD } & \multicolumn{2}{|c|}{ Skewness } & \multicolumn{2}{|c|}{ Kurtosis } \\
\cline { 6 - 9 } & & & & & Stat. & $\begin{array}{c}\text { Std. } \\
\text { Error }\end{array}$ & Stat. & $\begin{array}{c}\text { Std. } \\
\text { Error }\end{array}$ \\
\hline DMI_IEP1 & 1 & 4 & 4.02 & .933 & -.820 & .152 & .294 & .303 \\
\hline DMI_IEP2 & 1 & 4 & 3.78 & .904 & -.605 & .152 & .128 & .303 \\
\hline DMI_IEP3 & 2 & 4 & 4.23 & .738 & -.859 & .152 & .806 & .303 \\
\hline DMI_IEP4 & 1 & 4 & 3.17 & 1.148 & -.223 & .152 & -.935 & .303 \\
\hline DMI_IPL5 & 1 & 4 & 3.91 & .890 & -.771 & .152 & .363 & .303 \\
\hline DMI_IPL6 & 1 & 4 & 3.97 & .849 & -.871 & .152 & 1.032 & .303 \\
\hline DMI_IPL7 & 1 & 4 & 3.75 & .872 & -.670 & .152 & .376 & .303 \\
\hline DMI_IPL8 & 1 & 4 & 3.96 & .779 & -.541 & .152 & .377 & .303 \\
\hline DMI_EINV9 & 2 & 4 & 4.17 & .699 & -.597 & .152 & .422 & .303 \\
\hline DMI_EINV10 & 1 & 4 & 4.34 & .728 & -1.167 & .152 & 1.031 & .303 \\
\hline DMI_EINV11 & 1 & 4 & 3.87 & .980 & -.773 & .152 & .197 & .303 \\
\hline DMI_EINV 12 & 1 & 4 & 3.46 & .997 & -.631 & .152 & .124 & .303 \\
\hline
\end{tabular}

Source: Researchers' computation using SEM Lavaan software version 0.5

According to Pallant (2013), the skewness value indicates the symmetry of the distribution whilst the kurtosis value provides information on the 'peakedness' of the distribution.
When applying the rule of thumb, the skewness between -0.5 and 0.5 indicates that the data are fairly symmetrical, the values between -1 and -0.5 or between 0.5 and 1 indicate that the data are moderately skewed; and the values less than -1 or 
greater than 1 indicate that the data are highly skewed. The result shows that the data are moderately skewed as the values range between -1 and -0.5 or between 0.5 and 1 with the exception of a few items in the data.Table 3 presents the result from the Exploratory Factor Analysis (EFA) on the independent variables of the questionnaire items. The Maximum Likelihood Analysis (MLA) was first conducted on all the independent variables comprising 21 items with oblique rotation (Promax) as evidence from previous studies showed that variables correlate with each other. The Kaiser-Meyer-Olkin (KMO) measure verified the sampling adequacy for the analysis, KMO = .921 ('superb' according to Field, 2009), and all KMO values for individual items were $>.50$, which is well above the acceptable limit of 0.5 (Field, 2009). Bartlett's test of sphericity $\chi^{2}$ (496) $=4130.625, p<.001$ indicated that correlations between items were sufficiently large for MLA. An initial analysis was run to obtain eigen values for each component in the data. Factors with cross-loadings were deleted to ensure the undimensionality of the factors. The resultant analysis showed that three factors explained $53.224 \%$ of the variance.

Table 3. Exploratory factor analysis

\begin{tabular}{|c|c|c|c|c|}
\hline \multirow{2}{*}{} & \multicolumn{4}{|c|}{ Component } \\
\cline { 2 - 5 } & 1 & 2 & 3 & 4 \\
\hline DMI_IEP1 & .126 & .200 & .640 & .107 \\
\hline DMI_IEP2 & .147 & .180 & .624 & .110 \\
\hline DMI_IEP3 & .013 & .149 & .564 & .267 \\
\hline DMI_IEP4 & .224 & .019 & .676 & .131 \\
\hline DMI_IPL5 & .133 & .597 & .127 & .176 \\
\hline DMI_IPL6 & .201 & .601 & .163 & .208 \\
\hline DMI_IPL7 & .286 & .578 & .165 & .171 \\
\hline DMI_IPL8 & .268 & .584 & .164 & .148 \\
\hline DMI_EINV9 & .246 & .532 & .093 & .274 \\
\hline $\begin{array}{c}\text { DMI_EINV } \\
\text { 10 }\end{array}$ & .469 & .359 & .128 & .522 \\
\hline $\begin{array}{c}\text { DMI_EINV } \\
\text { 11 }\end{array}$ & .392 & .306 & .122 & .579 \\
\hline $\begin{array}{c}\text { DMI_EINV1 } \\
\text { 2 }\end{array}$ & .247 & .248 & .188 & .732 \\
\hline $\begin{array}{c}\text { Eigen } \\
\text { values }\end{array}$ & 11.57 & 2.296 & 1.791 & 1.369 \\
\hline
\end{tabular}

\begin{tabular}{|c|c|c|c|c|}
\hline $\begin{array}{c}\text { Percentage } \\
\text { of variance } \\
\text { explained }\end{array}$ & $\begin{array}{c}19.48 \\
1\end{array}$ & $\begin{array}{c}14.75 \\
2\end{array}$ & $\begin{array}{c}10.76 \\
9\end{array}$ & 8.222 \\
\hline $\begin{array}{c}\text { Cumulative } \\
\text { percentage } \\
\text { of variance } \\
\text { explained }\end{array}$ & 19.48 & 34.23 & 45.00 & 53.22 \\
2 & 2 & 4 \\
\hline
\end{tabular}

Source: Researchers' computation using SEM Lavaan software version 0.5

Table 3 shows the factor loadings for the independent variables of the study after rotation. The items that cluster on the same components suggest that factor 1 represents Employees' Productivity (EP), factor 2 Profitability Level (PL), and factor 3 Employees' Innovativeness (EINV).

\subsection{Cronbach Alpha}

Cronbach Alpha was adopted to test the reliability of the constructs.

Table 4. Reliability coefficients of main constructs

\begin{tabular}{|c|c|c|c|}
\hline Constructs & $\begin{array}{c}\text { No. of } \\
\text { items }\end{array}$ & $\begin{array}{c}\text { Internal } \\
\text { consistency }\end{array}$ & $\begin{array}{c}\text { Cronbach } \\
\text { Alpha }\end{array}$ \\
\hline 1.Gender & 2 & .768 & .703 \\
\hline 2.Age & 4 & .839 & .836 \\
\hline 3.Workingexperience & 5 & .816 & .818 \\
\hline $\begin{array}{c}\text { 4.Highest educational } \\
\text { experience }\end{array}$ & 5 & .900 & .894 \\
\hline 5.Tribe/ethnic group & 4 & .890 & .889 \\
\hline 6.DMI-ILP & 4 & .861 & .855 \\
\hline 7.DMI-IP & 4 & .823 & .821 \\
\hline 8.DMI-INV & 4 & .945 & .944 \\
\hline
\end{tabular}

Source: Researchers' computation using SEM Lavaan software version 0.5

The internal consistency of the items was measured by dividing the square of the summation of the factor loadings with the square of the summation of the factor loadings and summation of error variables. This procedure is similar to the Cronbach Alpha procedure but only taking into account the factor loadings of the items. The results of the internal consistency of the main constructs generally were above .60 and the Cronbach Alpha value exceeded .50, which is the recommended value, according to Nunnally (1978).

\subsection{Correlation results}

Table 5 revealed the results for the composite means, the standard deviations as well as the correlation of all the variables that constitute 
the constructs used in the study as well as the validity.

Table 5. Means, standard deviations, and inter-correlations

\begin{tabular}{|c|c|c|c|c|c|c|c|c|c|c|c|}
\hline Constructs & $M$ & $S D$ & 1 & 2 & 3 & 4 & 5 & 6 & 7 & 8 & 9 \\
\hline 1.Gender & 4.02 & .933 & 1 & & & & & & & & \\
\hline 2.Age & 3.78 & .904 & 0.057 & 1 & & & & & & & \\
\hline 3.Work exp. & 4.23 & .738 & 0.122 & $.307^{* *}$ & 1 & & & & & & \\
\hline 4. Education. & 3.17 & $\begin{array}{l}1.14 \\
8\end{array}$ & 0.118 & -0.012 & 0.107 & 1 & & & & & \\
\hline $\begin{array}{l}5 . \text { Tribe/Eth } \\
\text { nic group }\end{array}$ & 3.91 & .890 & 0.021 & -0.038 & $-.131^{*}$ & 0.095 & 1 & & & & \\
\hline 6.DMI-ILP & 3.97 & .849 & 0.082 & -0.107 & -0.016 & $.367^{* *}$ & -0.003 & 1 & & & \\
\hline 7.DMI-IP & 3.75 & .872 & -0.11 & 0.03 & 0.094 & $.325^{* *}$ & -0.108 & 0.032 & 1 & & \\
\hline 8.DMI-INV & 3.96 & .779 & 0.016 & $-.178^{* *}$ & 0.063 & $.386^{* *}$ & -0.068 & $.471^{* *}$ & $.221^{* *}$ & 1 & \\
\hline 9. Productivity & 4.08 & .722 & 0.046 & $-.184^{* *}$ & -0.066 & $.218^{* *}$ & $.244^{* *}$ & $.227^{* *}$ & 0.025 & $\begin{array}{l}.186^{*} \\
*\end{array}$ & 1 \\
\hline
\end{tabular}

$\mathrm{N}=256, p<.10,{ }^{*} p<.05,{ }^{* *} p<.01,{ }^{* * *} p<.001$

Source: Researchers' computation using SEM Lavaan software version 0.5

The means, standard deviations, and intercorrelations of all study variables are gender, age, the highest level of education, work experience, and tribe. The dependent variables are productivity, profitability, and innovativeness, while the independent variable is diversity management. The means score of all the constructs adopted in this study was computed to account for the variable that averaged the highest.The standard deviations of the variables were also measured to indicate the spread of the data or the closeness of the data to the central or various means, whereas correlation analysis was carried out to determine the strength and direction of the relationship between the variables. As revealed in the table, all the predictor variables had 256 responses while the composite means of all the variables ranged from3.17 to 4.08 . This implies that all the variables had a high composite mean value. This showed that the majority of the respondents agreed to the statements in the questionnaire. The results also showed that diversity management has a significant and positive correlation with productivity ( $\mathrm{r}=.367, \mathrm{p}<0.01)$, improved profitability $(\mathrm{r}=325, \mathrm{p}<0.01)$, and employees' innovativeness $(\mathrm{r}=.221, \mathrm{p}<0.01)$.

\subsection{Test of hypotheses}

The path coefficients are related to each hypothesized relationship in the model, as well as control variables. The control variables and the independent variables in the analysis account for $15.7 \%$ of the variance in organizational productivity $\left(R^{2}=.157\right)$. The study showed that the control variables, age $(\gamma$ $=.073, p<.01)$, work experience $(\gamma=.005, p<$ $.005)$, and educational qualification $(\gamma=.024$, $p<.005)$ were positively and significantly related to performance. Other control variables, such as gender $(\gamma=-.028, p>.05)$ and tribe/ethnic group ( $\gamma=-.151, p>.05)$, did not have a significant impact on performance.

The results imply that in the relationship between diversity management and organizational performance, certain controlled variables may interfere either proactively or retroactively. In this study, gender and tribe have a negative implication on productivity, especially when discriminated against. 
Table 6. Structural Equation Model (SEM) results

\begin{tabular}{|c|c|c|c|c|c|c|}
\hline Path From & Path To & Но & $\begin{array}{c}\text { Ho } \\
\text { sign }\end{array}$ & $\begin{array}{c}\text { Standardized } \\
\text { structural } \\
\text { coefficient } \\
\end{array}$ & $\begin{array}{c}\text { Statistical } \\
\text { significance }\end{array}$ & $R^{2}$ \\
\hline \multicolumn{7}{|l|}{$\gamma$ path } \\
\hline $\begin{array}{l}\text { Control } \\
\text { variables }\end{array}$ & & & & & & .037 \\
\hline 1.Gender & Organizational productivity & NA & --- & -.028 & $p>.05, \mathrm{n}$ 's & \\
\hline 2.Age & Organizational productivity & NA & --- & .073 & $p<.10$ & \\
\hline $\begin{array}{l}\text { 3.Working } \\
\text { experience }\end{array}$ & Organizational productivity & NA & --- & .005 & $p<.005$ & \\
\hline $\begin{array}{l}\text { 4.Highest } \\
\text { educational } \\
\text { experience }\end{array}$ & Organizational productivity & NA & --- & .024 & $p<.005$ & \\
\hline $\begin{array}{l}\text { 5.Tribe/ethnic } \\
\text { group }\end{array}$ & Organizational productivity & NA & --- & -.151 & $p>.05$ n.s & \\
\hline Main effects & & & & & & .12 \\
\hline 6.DMI-ILP & Organizational productivity & H01 & + & .367 & $p<.01$ & \\
\hline 7.DMI-IP & Organizational productivity & $\mathrm{H} 02$ & + & 1.384 & $p<.010$ & \\
\hline 8.DMI-INV & Organizational productivity & H03 & + & .430 & $P<.05$ & \\
\hline 9.DMI-PRD & Organizational productivity & $\mathrm{H} 04$ & + & .308 & $p<.05$ & \\
\hline
\end{tabular}

Sources: Researchers' computation with the aids of Structural Equation Model (SEM) Lavaan software version 0.5

The first hypothesis (H01) was formulated to predict whether or not diversity management has a significant impact on productivity. The result invalidated the first null hypothesis which implies that diversity management has a significant impact on the productivity of multinational companies $(\gamma=.367, p<.01)$. This implies that proper management of diversity in the workplace among the workforce will enhance the employees' productivity. The second hypothesis was also rejected based on the resulting outcome of the SEM which invalidated the null hypothesis. This implies that diversity management has a significant relationship with the profitability of multinational companies $(\gamma=1.384, p<.01)$. This is possible because proper diversity management gives employees peace of mind and a sense of belonging, which exceeds any limitation in carrying out their responsibilities and then translates to improved profitability. The third hypothesis indicated a significant and positive effect of diversity management on innovativeness $(\gamma=.042, p<.01)$. This result validated the alternate hypothesis as innovativeness is an individual thing and every individual possesses a degree of innovativeness. Given a conducive environment, the individual tends to be more innovative than in a hostile environment.

\section{Discussion of findings}

Nigeria is characterized by people from diverse origins, cultures, beliefs, and languages. Such differences sometimes instill barriers, suspicion, prejudice and bias, inequality, even gender, where women are not in leadership positions, to other forms of marginalization like perceptions of disabled job applicants (Lane \& Flowers, 2015). These are done either consciously or unconsciously, which has a negative implication on the workforce and subsequently affect productivity, profitability, and innovativeness (Jones et al., 2016). It becomes imperative for corporate organizations to identify and address cases of discrimination in the workplace, especially in multinational companies in Nigeria. The result of this study indicated that diversity management improves employees' productivity, innovativeness, and profitability performance. This is so because diversity management creates an enabling working environment where individual works with peace of mind. Such a working environment gives birth to improved performance (employee's productivity, profitability level, and employees' innovativeness). Thus, the primary task of human resources management is not solely hiring talents from different areas, but creating an environment that is conducive enough for different talents to blossom. The 
result of our study supports Greenberg (2012) who revealed that an organization's success and competitiveness depend upon its ability to embrace diversity. In Greenberg's (2012) opinion, productivity increases when workers work together as a team. Similarly, the study agrees with Hiranandani (2012), who found that diversity management improves employees' productivity, profitability, and innovativeness. All these are achieved by fostering creativity and innovation. In the present-day urban business environment, characterized by globalization, rapid change, and uncertainty, companies must adapt, change, and learn at an unprecedented pace in business history. Furthermore, the present study conforms to the study of Oliver (2005), who concluded that a rapidly shifting milieu, creative ideas, knowledge, and innovation are the only stable sources of capital.Therefore, developing a more diverse workforce assumes enormous significance in a competitive market situation due to its potential to harness a variety of perspectives, experiences, and insights, which is vital to business success and productivity. Given the expected benefits of workforce diversity as well as the associated challenges, diversity management is significant to sufficiently minimize the challenges while anchoring on the benefits associated with a diverse workforce to enhance efficiency and maximize profits (Inegbedion, Sunday, Asaleye, Lawal, \& Adebanji, 2020).

\section{Conclusion}

The objective of diversity management is to promote recognition, respect, and acceptance of the uniqueness of individuals due to the uniqueness in the dimensions of diversity. Recognizing the diverse environment through a mutual understanding and a deliberate effort of multinational companies to embrace the peculiarity of every employee remains the primary aim for diversity management. This has the potential of improving employees' productivity, profitability, and innovativeness. Also, multinational companies in Nigeria should embrace workplace diversity management since it was observed that the prevailing employee relationship has a significant effect on the diversity of workers. The study reveals that diversity management has its challenges; however, multinational companies stand to benefit a lot if effectively implemented.

\subsection{Recommendation for future research}

The present study recommends that multinational companies in Nigeria should foster a friendly and accommodating environment where equal rights and opportunities are given to diverse employees as this will improve employees' productivity, profitability level, and employees' innovativeness. Again, employees and employers should enjoy a reciprocated relationship where each satisfies the other and individual uniqueness is accordingly respected. Future research should make effort to investigate the impact of diversity management on performance in multinational companies in Nigeria and, if possible, in Africa. Also, the influence of diversity management and inclusion on the performance of multinational companies should be investigated to arrive at employees' satisfaction, attitude, and behavior in the workplace.

\subsection{Limitation of the previous research}

The review of the extant literature on diversity management has shown that previous studies have concentrated on diversity management and job satisfaction and performance. The present study has gone a little further by examining the influence of diversity management on three surrogates of performance (employees' productivity, employees' innovativeness, and profitability level). These surrogates are very significant to the survival of every organization. Furthermore, most of the previous studies on diversity management were based on case studies, making the generation of results on other organizations misleading. However, this study has sampled six different multinational companies in Lagos which made the study a survey and the outcome can be generalized to similar companies.

\subsection{Limitation of the research process}

The major limitation of this study is the sample drawn from six multinational companies in Lagos (although the largest multinational 
companies in Nigeria). To be able to generalize accurately from the results of the study, there is a need to investigate many more multinational companies in other parts of the country. Besides, the study should be undertaken in other parts of Africa with a less diverse workforce as it has been discovered that Nigeria has the highest diverse population in the African continent. The other limitation is the involvement of only three measurements of performance (employees' productivity, profitability level, and employees' innovativeness). There are other variables of performance that may be influenced by diversity management such as employees' satisfaction, corporate governance, and employees' participation in decision making, among others. However, employees' productivity, employees' innovativeness, and profitability level are germane to the survival and continuity of every business.

\section{References}

1. Ajiri, P., \& Odor, H. (2018) Managing diversity at work: Organizational Survival. European Journal of International Management, 10(16), 41-46.

2. Axtell, C.M., Holman, D.J., Ushworth, K.L., Wall, T.D., Waterson, P.E., \& Harrington, E. (2000) Shop floor innovation: facilitating the suggestion and implementation of ideas. Journal of Occupational and Organizational Psychology. 39, 599 - 617.

3. Choi, S. (2017) Workforce diversity and job satisfaction of the majority and the minority: Analyzing the Asymmetrical Effects of Relational Demography on Whites and Racial/Ethnic Minorities. Review of Public Personnel Administration. 37(1), 84-107.

4. Cunningham, G. (2009) The Moderating Effect of Diversity Strategy on the Relationship between Racial Diversity and Organizational Performance, Journal of Applied Social Psychology, 39, 1445 - 1460.

5. Damanpour, F. (1991) Organizational innovation: A meta-analysis of effects of determinant and moderators. Academy of Management Journal, 34, 555-590.

6. Dike, P. (2013) The impact of workplace diversity on organizations, Degree Thesis Degree Programme in International Business

7. Downey, N., Werff, L., Thomas, K.,\&Plaut, V. (2015) The role of diversity practices and inclusion in promoting trust and employee engagement, Applied Social Psychology, 1-10,
8. Ely, R., \& Thomas, D. (2001) Diversity at work: The effects of diversity perspectives on workgroup processes and outcomes. Administrative Science Quarterly, 46, 229 - 273.

9. Feldman, J. A. (2005) Factors of workforce diversity that influence individual and organizational performance, University of Pretoria, South Africa, Retrieved from http://upetd. up.ac.za/thesis/available/etd11112005-112310/

10. Fields, M. (2009) Managing diversity: Expert solutions to everyday challenges. Boston, MA: Harvard Business press.

11. Fink, J. S., Pastore, D. L., \& Riemer, H. A. (2001) Do differences make a difference? Managing diversity in Division 1-A intercollegiate athletics. Journal of Sports Management, 15, 10 15.

12. Fink, J. S., Pastore, D. L., \& Riemer, H. A. (2003) Managing employee diversity: Perceived practices and organizational outcomes in NCAA Division III athletic departments. Sports Management Review, 6, 147-168

13. Fornell, C., \& Larcker, D. F. (1981) Evaluating structural equations with unobservable variables and measurement error, Journal of Marketing Research (18), 39-50.

14. Gossen, J. (2016) Managing workplace diversity: Theory and practice within an interdisciplinary framework. Unpublished thesis, Athabasca, Alberta

15. Inegbedion, H. Eze, S., Asaleye, A., Lawal, A., \& Ayeni, A. (2018) Managing Diversity for Organizational Efficiency, SAGE Open, 1-10

16. Jabbour, C. Gordono, F., Oliveira, J., Martinez, J., \& Battistelle, R. (2011) Diversity management: Challenges, benefits, and the role of human resource management in Brazilian organizations. Equality, Diversity, and Inclusion: An International Journal. 30. 58-74.

17. Kanter, R. M. (2006) Confidence: How Winning and losing streaks begins and ends. New York: Crown Random House

18. Kanter, R. M. (1988) When a thousand flowers bloom: structural, collective, and social conditions for innovation in organizations, in Research. In B. Staw \& L. Cummings (Eds.), Research in organizational behavior (pp. 169-211). Greenwich, CT: JAI.

19. Kravitz, D.,\&Yuengling, R. (2011) The researchpractice gap: Diversity predicts performance. Retrieved from https://diverseeducation.com/article/16453/ (Accessed: October 25, 2020).

20. Kreitner, R., \& Kinicki, A. (2001) Organizational Behaviour. New York: McGraw-Hill.

21. Kundu, S. C., \& Mor, A. (2017) Workforce diversity and organizational performance: A 
study of the IT industry in India. Employee Relations, 39(2), 160-183.

22. Larkey, L. K. (1996) The development and validation of the workforce diversity questionnaire: An instrument to assess interactions in diverse workgroups. Management Communication Quarterly 9(3), 96-377.

23. Ndiang'ui, P. (2013) The Relationship between Diversity-Management Strategies and Organizational Performance of Florida Public High Schools, Unpublished thesis, Florida Gulf Coast University

24. Odita, A. O., \& Egbule, S., (2015) Workforce diversity and organizational effectiveness in Nigeria brewery industry. Developing country studies.5(8), 74-84.

25. Olabisi, J., Afolabi, A., Kajola, S. O., Ariyibi, 0. (2019) Effect of Currency Depreciation on Financial Performance of Nigerian Deposit Money Banks, Izvestiya Journal of Varna University of Economics.63(2), 104 - 116.

26. Olabisi, J., Soyemi, K. A., \& Omojola S. O. (2016) Cost management techniques and product quality in Nigerian Quoted Foods and Beverages Companies. Fountain University Journal of Management and Social Sciences, 5(2), 96-106.

27. Ogbo, A., Kifordu, A., \& Ukpere, W. (2014) The Effect of Workforce Diversity on Organizational Performance of Selected Firms in Nigeria, Mediterranean Journal of Social Sciences, 5(10), 231-236.

28. Ohunakin, F., Adeniji, A., Ogunnaike, O., Igbadume, F., \& Akintayo, D. (2019) The effects of diversity management and inclusion on organizational outcomes: a case of a multinational corporation, Business: Theory and Practice, 23, 93-102.

29. Ortlieb, R., \& Sieben, B. (2014) The making of inclusion as structuration: empirical evidence of a multinational company, equality, diversity, and inclusion. An International Journal, 33(3), 235-248.

30. Pallant, J. (2013) SPSS Survival Guide: A Step by Step Guide to Data Analysis using IBM SPSS, $5^{\text {th }}$ ed., Open University Press, Australia.

31. Panda, S. (2010) Managing cultural diversitystrategies for organizational success, Journal of Contemporary Research in Management, 5(3), 917.

32. Rahman, A., Qayum, A., \& Afza, T. (2011) Sectorwise performance of working capital management measures and profitability using ratio analysis, Interdisciplinary Journal of Contemporary Research in Business.3(8), 56-67

33. Ramamoorthy, N., Flood, P.C., Slattery, T., \& Sardessai, R. (2005) Determinants of innovative work behaviour: Development and test of an integrated model. Creativity and Innovation Management, 14(2), 142-150.

34. Richard, C. O. (2000) Racial diversity, business strategy, and firm performance: A resourcebased view. Academy of Management Journal, 43(2), 164-177.

35. Sabharwal, M. (2014). Is diversity management sufficient? Organizational inclusion to furtherperformance, Public Personnel Management, 43(2), 193-21

36. Samuel, A.P., \& Odor, H.O. (2018) Managing diversity at work: Key to organizational survival. European Journal of Business and Management, 10(16), 41-46.

37. Schultz, H., Bagraim, J., Potgieter, T., Viegde, C., \& Werner, A. (2003) Organizational behavior. Pretoria: Van Schaik. Thomas

38. Society for Human Resource Management (2009) Global Diversity and inclusion: perceptions, practices, and attitudes: a study for the society for human resource management. Alexandria: The Economist Intelligence Unit.

39. Suri, S., \& Sharma, M. L. (2011) Diversity management and organizational effectiveness in Indian organizations. International Journal of Research in Commerce and Management, 2(11), 91-95. 